\title{
Analysis of metallic traces from biodegradation of endomedullary AZ31 alloy temporary implants in rat organs after long implantation times
}

O.G. Bodelón ${ }^{1}$, C. Iglesias $^{2}$, J. Garrido $^{3}$, C. Clemente ${ }^{4}$, M.C. Garcia-Alonso ${ }^{1}$ and M.L. Escudero ${ }^{1 *}$

1 Department of Surface Engineering, Corrosion and Durability, National Centre for Metallurgical Research (CENIM), CSIC, Madrid, Spain.

2

La Paz Hospital, Madrid, Spain.

3 Department of Social Psychology, Autonoma University of Madrid (UAM), Madrid, Spain.

4 Department of Human Anatomy and Embryology, School of Medicine, University of Alcala, Alcalá de Henares, Spain.

* Corresponding author: M.L. Escudero, Department of Surface Engineering, Corrosion and Durability, National Centre for Metallurgical Research (CENIM), CSIC, Avda. Gregorio del Amo 8. 28040 Madrid. Spain. Phone number: +34 915538 900. Telefax: +34 915347425.

e-mail: escudero@cenim.csic.es.

Keywords: AZ31 biodegradation, metallic traces, animal model, bone repair, osteosynthesis.

\begin{abstract}
AZ31 alloy has been tested as a biodegradable material in the form of endomedullary implants in female Wistar rat femurs. In order to evaluate the accumulation of potentially toxic elements from biodegradation of the implant, magnesium $(\mathrm{Mg})$, aluminium $(\mathrm{Al})$, zinc $(\mathrm{Zn})$, manganese $(\mathrm{Mn})$ and fluorine $(\mathrm{F})$ levels have been measured in different organs such as kidneys, liver, lungs, spleen and brain. Several factors that may influence accumulation have been taken into account: how long the implant has been in place, whether or not the bone is fractured, and the presence of a $\mathrm{MgF}_{2}$ protective coating on the implant. The main conclusions and the clinical relevance of the study have been that AZ31 endomedullary implants have a degradation rate of about $60 \%$ after 13 months,
\end{abstract}


which is fully compatible with fracture consolidation. Neither bone fracture nor $\mathrm{MgF}_{2}$ coating seems to influence the accumulation of trace elements in the studied organs. Aluminium is the only alloying element in this study that requires special attention. The increase in Al recovered from the sampled organs represents $3.95 \%$ of the amount contained in the AZ31 implant. Al accumulates in a statistically significant way in all the organs except the brain. All of this suggests that in long term tests AZ31 may be a suitable material for osteosynthesis. 


\section{Introduction}

Orthopaedic and cardiovascular medicine are generating a growing demand for medical devices (Manuel and Hort, 2011). In temporary orthopaedic and trauma surgery implants, magnesium (Mg) and its alloys exhibit better load-bearing mechanical properties than other biodegradable materials like polymers and ceramics (Blaker et al., 2005; Rezwan et al., 2006). They also have very similar elastic modulus and density values to bone (Staiger et al., 2006), thus avoiding the occurrence of stress shielding. $\mathrm{Mg}$ and its alloys are furthermore of great interest because they do not need to be removed after fulfilling their purpose, being resorbable materials (Witte et al., 2008). Their biodegradation process gives rise to corrosion products (ion release) that may be deposited on the implant surface or around the implant site, and may also emigrate and be recovered in urine, blood, plasma and in different organs far away from the implant. According to the current state of the art, the decomposition or corrosion products of a magnesium implant do not generally pose a health hazard. Only a burst release of these products, which could overburden the organism's regulating mechanisms and therefore lead to local physiologically detrimental conditions, is to be considered a problem (Seitz et al., 2014).

This research considers the commercial alloy AZ31, whose mechanical properties and corrosion resistance are superior to pure $\mathrm{Mg}$ (Carboneras et al., 2011a; Carboneras et al., 2010), but whose biodegradation process gives rise not only to $\mathrm{Mg}$ corrosion products but also to those of zinc $(\mathrm{Zn})$, aluminium (Al) and manganese (Mn). The latter, which is not included as an alloying element, may be considered a contaminant that originates in the manufacturing process (Alvarez-Lopez et al., 2010). It is essential that all the released traces do not reach toxic levels (Feyerabend et al., 2006; Harper and Eley, 2002; Valentini et al., 2007), an aspect that is not often studied in $\mathrm{Mg}$ and its alloys (Yuen and Ip, 2010). The most controversial element incorporated in the AZ31 alloy is Al. For some researchers, $\mathrm{Al}$ is suspected of playing a major role during the development of 
Alzheimer's disease (Bulat et al., 2008; Seitz et al., 2014), Parkinson's and dementia (Erasmus et al., 1995), is potentially neurotoxic in humans and laboratory animals (El-Demerdash, 2004) or produces reactive oxygen species (ROS) and free radicals (Nehru and Anand, 2005; Ranjbar et al., 2008). Thus it would be desirable to know where and in what amounts the released ions accumulate.

In order to approximate clinical practice, we fractured a left femoral diaphysis in each rat and then fitted it with an AZ31 implant. In other in vivo studies, Mg material was transcortically inserted (Castellani et al., 2011; Fischerauer et al., 2013; Kraus et al., 2012) but not in an endomedullary way, that is, as for repair of a real fracture.

Both long term in vivo studies and the quantification of metallic trace accumulation in organs are scarce in the consulted literature (Schilling et al., 2013). Most of them consisted of the study of histological and pathological changes (Dziuba et al., 2013; He et al., 2009). The time factor for in vivo experimentation with $\mathrm{Mg}$ and its alloys does not usually go beyond 3 to 6 months (Kraus et al., 2012; Witte et al., 2006). In the present research it was decided to analyse metallic traces in rat organs, far away from the implant, originating in the biodegradation process of AZ31 alloy for a longer implantation time (13 months).

On the other hand, promising results from previous in vitro studies carried out by this research group using AZ31 alloy with $\mathrm{MgF}_{2}$ coating (Carboneras et al., 2010; Carboneras et al., 2011b; Lozano et al., 2013) led us to also consider the influence of this coating in the present work. This research line seeks to evaluate metallic traces such as $\mathrm{Mg}, \mathrm{Al}, \mathrm{Zn}, \mathrm{Mn}$ and fluorine (F) in different rat organs, such as the liver, kidneys, spleen, lungs and brain, resulting from the biodegradation process of AZ31 alloy intramedullary pins. It also studies the influence of different factors on the accumulation of these traces: how long the implant has been in place, whether or not the bone is previously fractured, and the presence of a protective coating on the implant. 


\section{Materials and methods}

\section{The implants}

The AZ31 alloy was received from Magnesium Elektron Ltd. in the form of a rolled $3 \mathrm{~mm}$ thick sheet in O-temper condition (annealed at $345^{\circ} \mathrm{C}$ ). The chemical composition of the AZ31 alloy was determined by wave length dispersion X-ray fluorescence (WDXRF) to be: $3.37 \pm 0.09$ wt.\% Al, $0.78 \pm 0.04$ wt. $\% \mathrm{Zn}, 0.22 \pm 0.01$ wt. $\% \mathrm{Mn}$ (balance $\mathrm{Mg}$ ). AZ31 was machined to form cylinders of $20 \mathrm{~mm}$ in length and $1 \mathrm{~mm}$ in diameter, with an average weight of $28.0 \pm 0.3 \mathrm{mg}$. The cylindrical specimens were rounded at both ends in order to eliminate sharp edges, to facilitate their insertion in the laboratory animals, and to avoid edge effects on the degradation rate. To enhance the corrosion resistance of AZ31 alloy, half of the pins were subjected to a chemical conversion treatment applied by immersion of the AZ31 substrates in $48 \mathrm{wt} . \% \mathrm{HF}$ solution at room temperature for 24 hours (Alvarez-Lopez et al., 2010; Chiu et al., 2007), followed by rinsing with deionised water and drying in a stream of warm air. This treatment gave rise to the $\mathrm{MgF}_{2}$ protective layer. All samples were gamma-ray sterilised.

\section{Surgery}

The animals used in the experiments were 45 female Wistar rats of three months of age and approximately $200 \mathrm{~g}$ body weight (bw). The animals were treated in accordance with European Union Guidelines for Ethical Care of Animals (86/609CEE) and Spanish Regulation (RD $1201 / 2005)$.

The scheme of Fig. 1 shows the experimental procedure followed in the in vivo tests. The animals were classified into two main groups: 9 control rats without implant insertion and without surgery; and 36 rats with an AZ31 alloy implant. Half of the second group (18 rats) were subjected to a femur fracture of their hind left leg by a unicortical cut with a Gillies saw followed by manual breakage of the other cortical, and immediately afterwards the implant was inserted inside the bone 
as an intramedullary pin for fracture reduction. The other half (18 rats) were not subjected to any fracture, but the AZ31 alloy implant was inserted by identifying the femoral condyles and drilling an orifice of $1.1 \mathrm{~mm}$ in diameter through the intercondylar notch to the central marrow channel. Half of the inserted implants were previously subjected to HF treatment and the other half remained untreated.

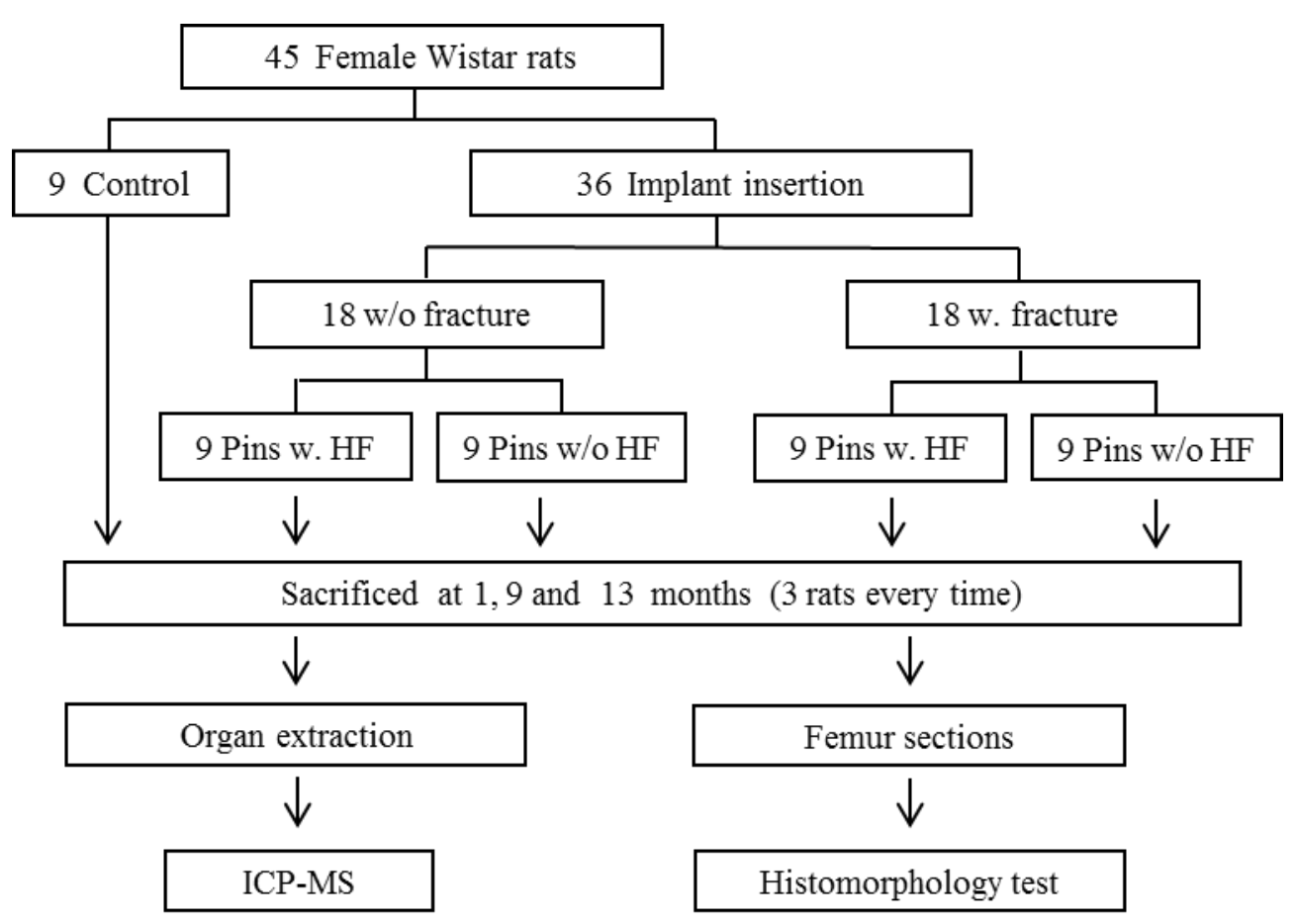

Fig. 1: Experimental procedure diagram

Following the operation, each rat received a prophylactic dose of analgesics and antibiotics: $5 \mathrm{mg}$ Enrofloxacin (BAYTRIL ${ }^{\circledR}, 10 \mathrm{mg} / \mathrm{kg}$ ) and Meloxicam $\left(\right.$ METACAM $^{\circledR}, 2 \mathrm{mg} / \mathrm{kg}$ ), both in a single dose via subcutaneous injection. All the animals were kept in standard animal house conditions. Food and water were available $a d$ lib.

Upon completion of the scheduled monitoring times of 1,9 and 13 months, the rats were euthanized by intraperitoneal injection of $0.4 \mathrm{mg}$ sodium pentobarbital (Dolethal®) diluted in serum to proceed to extraction of the organs and their subsequent chemical analysis by Inductively Coupled Plasma Mass Spectrometry (ICP-MS). The femurs with implants were also extracted in order to carry out 
histomorphometric analysis and biodegradation evolution of the AZ31 alloy implants with implantation time.

\section{Sample preparation from the retrieved organs}

Several organs were retrieved: kidneys, livers, lungs, spleens and brains. Operations were performed on a clean bench using only zirconia scissors and plastic tweezers in order to avoid any contamination with metals. After removal, the organs were frozen first to $-20{ }^{\circ} \mathrm{C}$ and then to $-80{ }^{\circ} \mathrm{C}$ and freeze-dried for 72 hours with a Benchtop 6K freeze dryer (VirTis, SP Scientific, New York, USA).

Dry organ average weights (in g) were: liver (5.48 \pm 1.23$)$, lungs $(0.66 \pm 0.17)$, brain $(0.38 \pm 0.08)$, kidneys $(0.66 \pm 0.11)$ and spleen $(0.27 \pm 0.07)$. The samples were subsequently homogenised and powdered with a glass ball tube drive mill (Ika Ultra-Turrax, Staufen, Germany). A $0.2 \mathrm{~g}$ aliquot of each sample was digested in a $50 \mathrm{~mL}$ mix ( $40 \mathrm{~mL}$ distilled water, $8 \mathrm{~mL} \mathrm{HNO}_{3}$ and $2 \mathrm{~mL} \mathrm{H}_{2} \mathrm{O}_{2}$ ) and then placed in closed high-pressure HPV 80 type vessels and slowly heated to $200{ }^{\circ} \mathrm{C}$ in an Ethos Sel 1600 URM Microwave (Milestone, Connecticut, USA) and kept at that temperature for 10 minutes.

ICP-MS analysis

To identify the different types of metallic traces lodged in the rat organs, each solution was analysed with an ELAN 6000 PE Sciex ICP mass spectrometer (Perkin-Elmer, Massachusetts, USA). The use of Inductively Coupled Plasma Mass Spectrometry (ICP-MS), which combines the exceptional characteristics of ICP for the atomisation and ionisation of the injected sample with the sensitivity and selectivity of MS, has been widely used in the determination of elements at trace and ultra-trace levels in different materials (Coedo et al., 1996; Okazaki and Goth, 2008; Okazaki et al., 2004; Rubio et al., 2008; Sarmiento-Gonzalez et al., 2009).

Analyses were performed for the following metallic elements: $\mathrm{Mg}, \mathrm{Al}, \mathrm{Zn}$ and $\mathrm{Mn}$. The latter was evaluated because of intermetallic contamination in the form of $\mathrm{Al}_{6} \mathrm{Mn}$ from the manufacturing 
process (Alvarez-Lopez et al., 2010). The detection limit calculated on the basis of the standard deviation of ten successive measurements of the blank solution, using the $3 \sigma$ criterion, was $0.2 \mathrm{ppm}$. Control tissues were obtained from the rats not subjected to any kind of implant, but also living in the same conditions and the same experimental time as the rats with implants. Technical precision was monitored with NIST Bovine liver standard (SRM 1577b) for Mg, Al, Zn and Mn quantification. The results were normalised in relation to sample weight.

\section{Fluorine analysis}

The analysis of fluorine was not possible by ICP-MS because its ionisation potential is higher than that of argon. For this reason, the analysis was performed using an Orion 9409BN fluoride ionselective electrode coupled to an Orion model 720A+ multimeter (Thermo Fisher Scientific, Massachusetts, USA). The analysis was carried out in the solutions obtained from acid digestion of the different organs. According to Inkielewicz and Krechniak (2003), a volume of Total Ionic Strength Adjustment Buffer (TISAB IV) was added to each sample to avoid fluoride complexation by iron $(\mathrm{Fe})$ and $\mathrm{Mg}$ ions. TISAB IV maintains the $\mathrm{pH}$ under 8, protecting from interferences given by $\mathrm{Fe}$ and $\mathrm{Mg}$ concentrations no higher than $100 \mathrm{ppm}$. Since the $\mathrm{Fe}$ and $\mathrm{Mg}$ concentrations analysed by ICP-MS in liver samples were as high as $360 \mathrm{ppm}$ and $550 \mathrm{ppm}$, respectively, the samples were diluted 10 times in milli-Q water before analysis. The calibration curve was performed with $\mathrm{NaF}$ as standard, with the same TISAB IV conditions used in the analysis of the organ samples.

\section{Histomorphometric analysis}

In order to test the evolution of biodegradation by histomorphometric analysis, the rat femurs of the rats, were extracted and fixed in $10 \%$ buffered $\mathrm{pH} 7$ formaldehyde and dehydrated in grading hydroxyethylmetacrylate resin concentrations, as mentioned in Donath and Breuner's method (Donath and Breuner, 1982). The femurs were cut into blocks and then embedded in Technovit ${ }^{\circledR}$ resin. The cutting and grinding of hard tissues was performed with an EXAKT sawing machine and 
grinding equipment (Leica Microsystems, Wetzlar, Germany). Five cross sections of about $50 \mu \mathrm{m}$ thickness were obtained from each femur.

Cross sections were stained with Masson trichrome makes it possible to appreciate the uncalcified osteoid tissue (orange), the calcified mature bone tissue (green) and the cell nuclei (dark red). The stained cross sections of femurs with implants were studied with an optical microscope (Carl Zeiss Microscopy GmbH, Göttingen, Germany). The images were transferred to MIP 4 software (Micron Image Processing Software, Digital Image Systems, Barcelona, Spain) to carry out the histomorphometric analysis. This software identifies the initial area occupied by the implant which is easily recognised by the circle of new tissue around it (Fig. 2a and b), and highlights the remaining AZ31 alloy implant by colour density so the loss of implant in each section can be calculated.

\section{Statistics}

The data obtained in the determination of metallic traces in the various organs was summarised as mean \pm standard deviation (S.D.). T-tests or Mann-Whitney tests were used to compare two independent groups. ANOVA for repeated measures and pairwise comparison with Bonferroni correction were used to compare means at different time-points. $\rho$-values $\leq 0.05$ were considered as significant. Statistical analysis was performed with Statgraphics Online.

\section{Results}

Histomorphometric analysis was used to evaluate the biodegradation process of the implants inside the bone. Fig. 2 shows the representative cross-section histomorphometric images at different magnifications of the partially resorbed untreated AZ31 implants in fractured femurs (a) and HF treated pins (b) stained with Masson trichrome after 1, 9 and 13 months from insertion, and (c) the percentage of implant resorption with implantation time for untreated and HF treated pins, respectively. 
a)
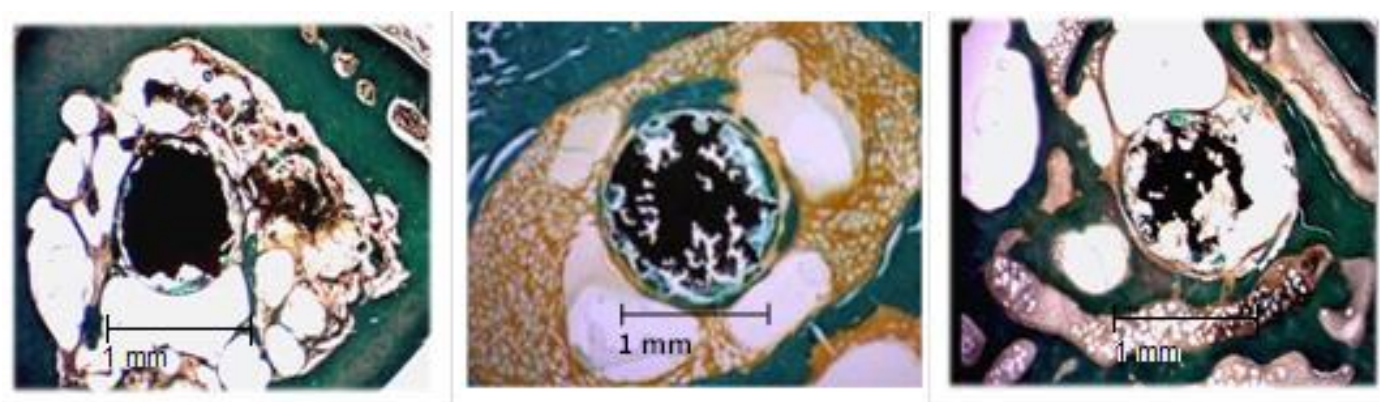

b)

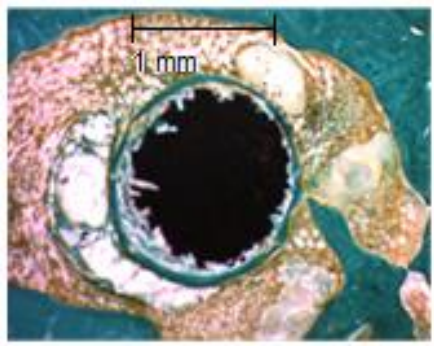

1 month

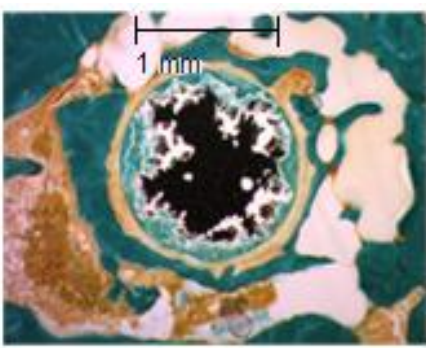

9 months

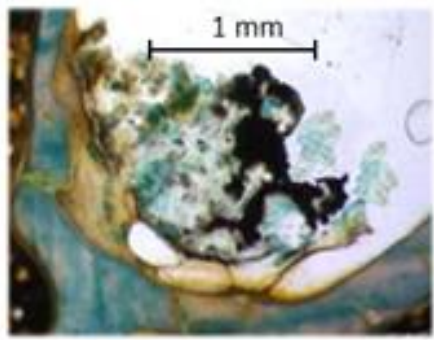

13 months

c)

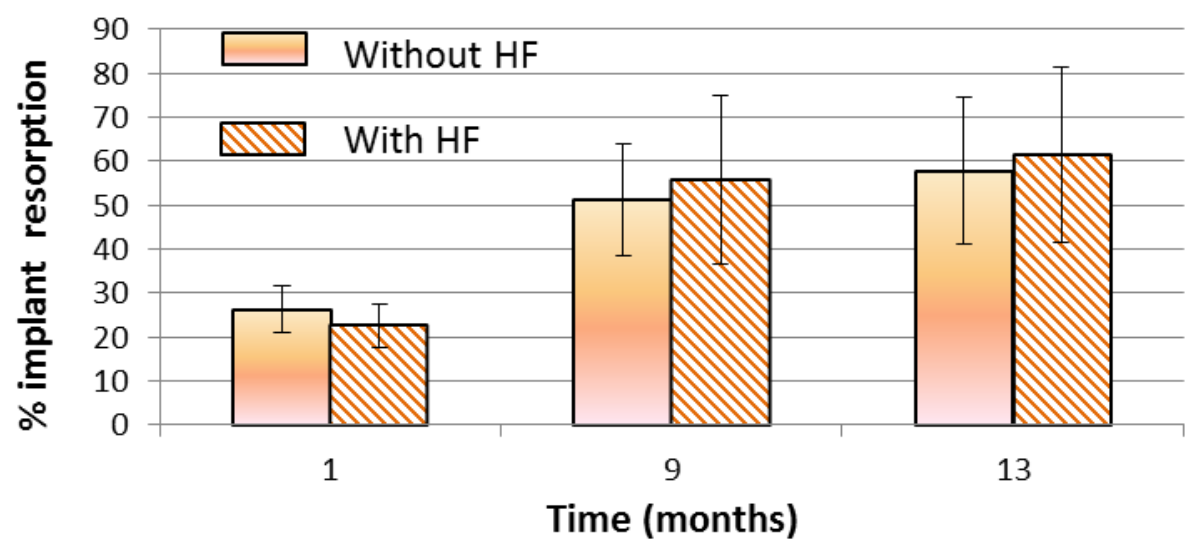

Fig. 2: Cross-section histomorphometric images of a) untreated AZ31 and b) HF treated AZ31 pins, stained with Masson trichrome after 1, 9 and 13 months from insertion (left to right). Central black area is the implant and green area is the cortical bone. c) Percentage of implant resorption for untreated and treated AZ31 pins with time.

The AZ31 implant, in black, can be easily identified in the centre of each image, surrounded by a fine film of connective tissue separating the medullary cavity. The cavity is partially occupied by trabeculae bone (green), abundant fat cells with a dark meshed shade and fibres of connective tissue (orange) whereas implant appears in black. The periphery of the image is occupied by mature cortical bone (green) that provides evidence of bone neoformation in the medullary cavity, distinguishing a thick trabecula of cortical bone and bone marrow of an orange coloured dotted 
appearance. It is interesting to note how the edges of the implant exhibit pitting corrosion that gives the surface a sawtooth appearance. Biodegradation starts at the outer surface of the pins and progresses towards their centre. The resorbable zones that surround the surface of the implant are being occupied by corrosion products composed of inorganic compounds, $\mathrm{Mg}$ oxides and hydroxides, observed in Fig. 2a and b as grey areas. No foreign body cells or inflammatory signs have been noticed in any of the samples.

Tomography images show that new bone is formed around all $\mathrm{Mg}$ implants. Even more, in the presence of ongoing corrosion, high levels of bone-device contact are observed after 9 and 13 months in vivo that have been also verified by computed tomography images (Iglesias et al., 2015). After 9 months, mature healing is observed, with full thickness bone around the pins at 9 and 13 months. This bone forming ability is in agreement with the results published by A. Chaya et. al who state that the results of in vivo degradation of $\mathrm{Mg}$ devices provide stabilization to facilitate healing, while degrading and stimulating new bone formation (Chaya et al., 2015). A similar behavior was observed by Kraus et al. with WZ21 alloys who state that the bone function does not seem to be harmed, the bone recovered surprisingly quickly after WZ21 pin degradation and kept its integrity for more than 4 weeks showing good osteoconductive properties by enhancing bone accumulation at the pin surface (Kraus et al., 2012).

Fig. 2c quantifies the implant resorption percentages for untreated and HF treated pins after 1, 9 and 13 months. There were no statistically significant differences in the resorption between the untreated and HF treated implants. At the beginning of implantation the implant surface is immersed in the physiological medium, rich in $\mathrm{Cl}$ and inorganic salts that promote the interaction with the surface and biocorrosion starts on the surface. The cathodic reaction produces not only hydrogen gas but also $\mathrm{OH}^{-}$ions which induces the precipitation of magnesium oxy-hydroxide compounds. These compounds act as a barrier that prevents the ingress of electrolyte and slow down the corrosion. During the first two months the volume of gas pockets produced around the 
AZ31 implant and measured by computed tomography are appreciable as could be seen in a previous work (Iglesias et al., 2015). The gas volume measured is drastically reduced at longer implantation time until the end of experimentation (13 months).

On the other hand, the $\mathrm{MgF}_{2}$ coating does not exert influence on the degradation process at the long implantation times studied in the work. This result can be explained taking into consideration that the continuous contact of physiological medium with the $\mathrm{MgF}_{2}$ coating finally gives rise to the degradation of the coating exposing the bare implant to the physiological medium. The electrochemical potential of both, $\mathrm{MgF}_{2}$ and $\mathrm{AZ31}$ surfaces are very different as could be verified by Scanning Kelvin probe (SKP) in a previous work (Carboneras et al., 2010) giving rise to the formation of galvanic couples that accelerate the corrosion on the implant surface.

The influence of implantation time on the accumulation of metallic traces in the complete set of the organs of the rats after 1, 9 and 13 months of implantation time is shown in Figure 3, for $\mathrm{Mg}$ and $\mathrm{Zn}$ (a), and $\mathrm{Mn}$ and $\mathrm{Al}(\mathrm{b})$.

a)

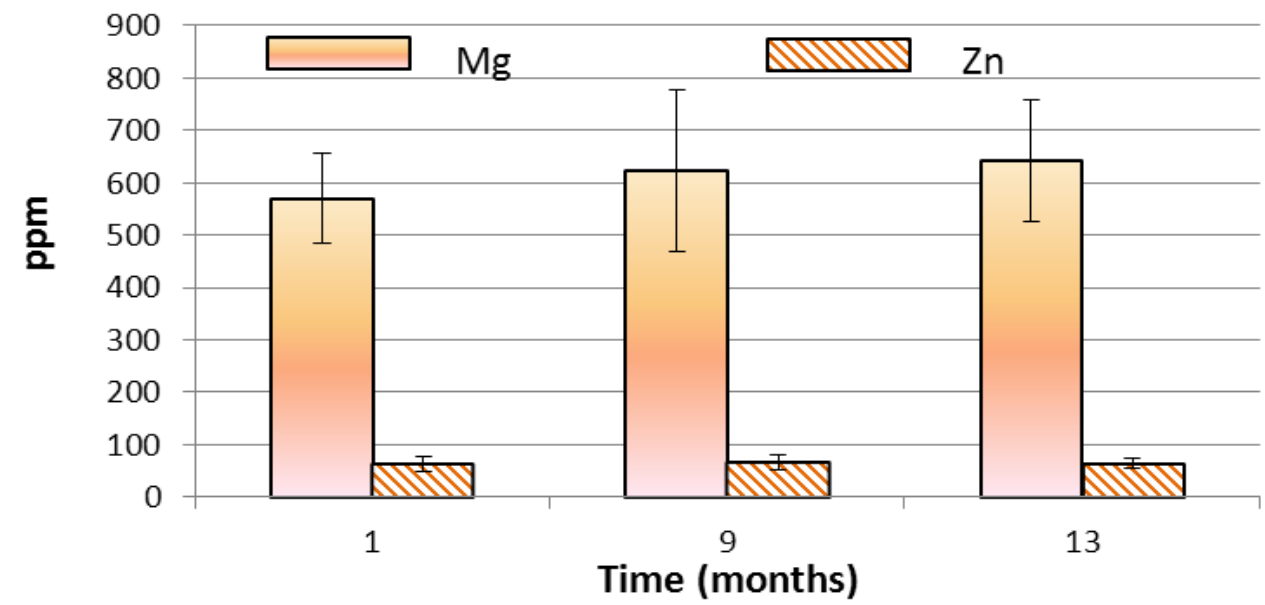


b)

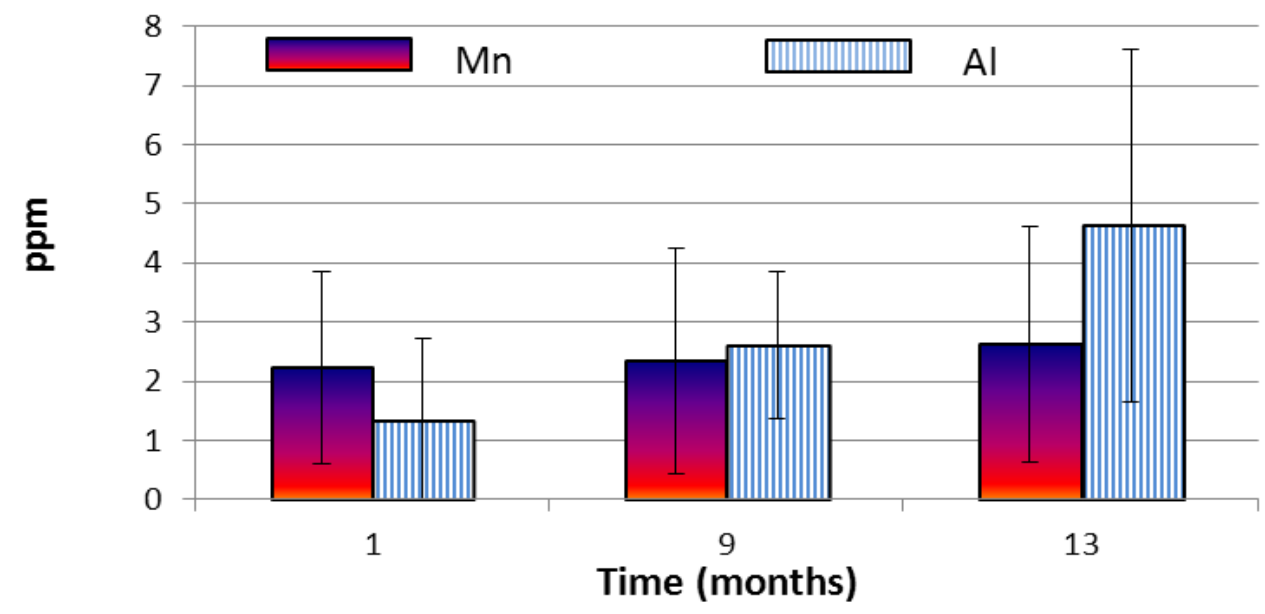

Fig. 3: Metallic traces in the complete set of the organs of the rats after 1, 9 and 13 months of implantation time: a) $\mathrm{Mg}$ and $\mathrm{Zn}$; b) $\mathrm{Mn}$ and $\mathrm{Al}$.

The data show higher $\mathrm{Mg}, \mathrm{Al}$ and $\mathrm{Mn}$ contents as time increases and the stabilisation of $\mathrm{Zn}$ values. This increase over time is not statistically significant except in the case of $\mathrm{Al}$, which continues to increase in the last period ( 9 to 13 months).

In order to exclude the possibility that the increase in metallic traces with implantation time may be due to other factors not related with the insertion of the AZ31 alloy implant, a comparison was made between the metallic traces analysed in the control rats (without implant but same age) and the rats with implants at 13 months. The results obtained are set out in columns (a) and (b) of Table 1. After a long implantation time, higher metallic trace levels are seen in the rats with AZ31 endomedullary implants than in the control rats, thus confirming that degradation of the implant material takes place and that metallic traces have migrated and accumulated in the different organs.

\begin{tabular}{|c|c|c|c|c|}
\hline & \multicolumn{2}{|c|}{$\begin{array}{l}\text { With implant } \\
\text { (a) }\end{array}$} & \multicolumn{2}{|c|}{$\begin{array}{l}\text { Without implant } \\
\text { (b) }\end{array}$} \\
\hline & Mean & S.D. & Mean & S.D. \\
\hline $\mathrm{Mg}$ & 641.08 & 115.32 & 563.60 & 111.72 \\
\hline $\mathrm{Al}$ & $\Omega_{4.64}$ & 2.98 & $\Omega 0.81$ & 0.75 \\
\hline $\mathrm{Mn}$ & 2.62 & 2.00 & 2.13 & 1.98 \\
\hline $\mathrm{Zn}$ & 65.37 & 10.38 & 64.41 & 11.28 \\
\hline
\end{tabular}

- =Data in ppm. $\quad \Omega=$ Significant difference at 0.95 confidence level. 
Table 1: Metal element contents in rats with implant (a), and in control rats [b] without implant, at the longest time (13 months).

Taking into account possible toxicity problems related with $\mathrm{Al}$, together with its statistically significant difference, an exhaustive analysis has been made of its presence in the different organs. Fig. 4 shows the distribution of Al content in each analysed organ from 1 to 13 months of implantation time.

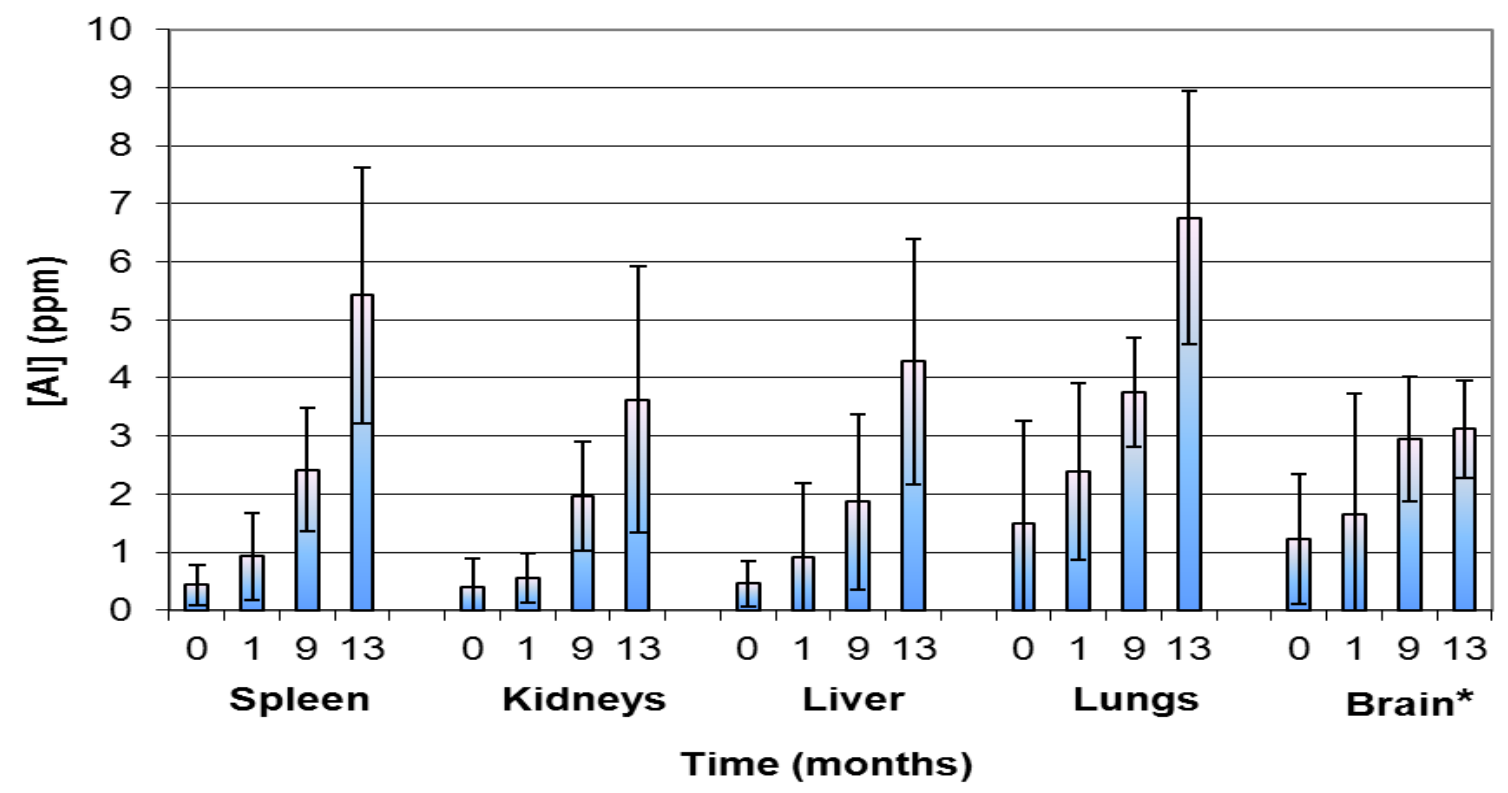

Fig. 4: Aluminium content in organs of rats euthanized after different implantation times. Bars mean S.D. $*=$ Brain is the only organ with no significant difference between 0 and 13 months (at 0.95 confidence level).

The $\mathrm{Al}$ content has risen in all the rat organs and is seen to accumulate most in the lungs (almost 7 ppm) followed by the spleen $(5.4 \mathrm{ppm})$. In the case of the brain, there seems to be a certain stabilisation after the ninth month. The brain is the only organ that does not show significant differences in Al content (ANOVA > 0.05) between 0 and 13 months (Fig. 4). 
Table 2 shows the Al content in different organs for both the control rats and those fitted with implants.

\begin{tabular}{|c|c|c|c|c|c|c|c|}
\hline & $\begin{array}{l}\text { Without } \\
\text { implant }\end{array}$ & $\begin{array}{c}\text { With } \\
\text { implant }\end{array}$ & ANOVA & $\begin{array}{l}\Delta \mathbf{A l} \\
(\mathbf{p p m})\end{array}$ & $\begin{array}{c}\text { Dry organ } \\
\text { (mg) }\end{array}$ & $\begin{array}{l}\Delta \mathbf{A l} \\
(\mathbf{m g})\end{array}$ & $\begin{array}{l}\% \text { pin Al } \\
\text { recovered }\end{array}$ \\
\hline & $\begin{array}{l}\text { Mean } \\
\pm \text { S.D }\end{array}$ & $\begin{array}{l}\text { Mean } \\
\pm \text { S.D }\end{array}$ & $\rho$ & [a] & [b] & [c] & [d] \\
\hline Spleen & $0.44 \pm 0.35$ & $5.42 \pm 4.98$ & $0.012 *$ & 4.98 & $353 \pm 16$ & $1.76 \mathrm{E}-03$ & 0.31 \\
\hline Kidney & $0.41 \pm 0.48$ & $3.62 \pm 3.21$ & $0.028^{*}$ & 3.21 & $671 \pm 15$ & $2.15 \mathrm{E}-03$ & 0.38 \\
\hline Liver & $0.46 \pm 0.39$ & $4.27 \pm 3.81$ & $0.017 *$ & 3.81 & $4114 \pm 93$ & $15.67 \mathrm{E}-03$ & 2.77 \\
\hline Lung & $1.50 \pm 1.76$ & $6.76 \pm 5.26$ & $0.031 *$ & 5.26 & $410 \pm 38$ & $2.16 \mathrm{E}-03$ & 0.38 \\
\hline Brain & $1.22 \pm 1.12$ & $3.11 \pm 1.90$ & 0.331 & 1.90 & $321 \pm 66$ & $6.10 \mathrm{E}-04$ & 0.11 \\
\hline$\Sigma$ organs & & & & & & $22.35 \mathrm{E}-03$ & 3.95 \\
\hline
\end{tabular}

Data in ppm (dry weight). $*=$ significant difference at 0.95 confidence level.

Table 2: Aluminium content in different organs of control rats and rats with implants after 13 months: [a] mean increment, from differences between rats with and without implants, [b] mean weight of dry organs, [c] $\mathrm{Al}$ increase (in $\mathrm{mg}$ ), calculated as [a] $\mathrm{x}$ [b] data, [d] recovered $\mathrm{Al}$ percentage respect to original whole implant $\mathrm{Al}$ mass.

To quantify the $\mathrm{Al}$ percentage recovered from the organ, the following calculation was performed: the mean weight of the implant is $28 \mathrm{mg}$, of which $3.37 \%$ is $\mathrm{Al}$, so the AZ31 alloy implant contains $0.94 \mathrm{mg} \mathrm{Al}$. Considering that the biodegradation of the implant after 13 months is about $60 \%$, the released $\mathrm{Al}$ is $0.57 \mathrm{mg}$. If the $\mathrm{Al}$ increase (column [a] of Table 2) is normalised considering the weight by organ (column [b] of Table 2) the $\mathrm{Al}$ increase in mg is obtained (column $[\mathrm{c}]=[\mathrm{a}] \mathrm{x}[\mathrm{b}]$ of Table 2). The last column is the Al percentage recovered from each organ (column [d] of Table 2).

The innovative aspect of the research carried out in this work is that it seeks to approximate a real situation of use of this material in fracture osteosynthesis. Pairwise comparisons were made between rats with and without fracture for each element and organ. As all the ANOVA results were 
in excess of 0.05 , no significant differences were found (at $95 \%$ confidence) that can be attributed to the fracture factor.

With regard to the last variable analysed in this study, the influence of prior treatment of the AZ31 implants with HF, Fig. 5 compares the F content in the organs of rats euthanized after 13 months.

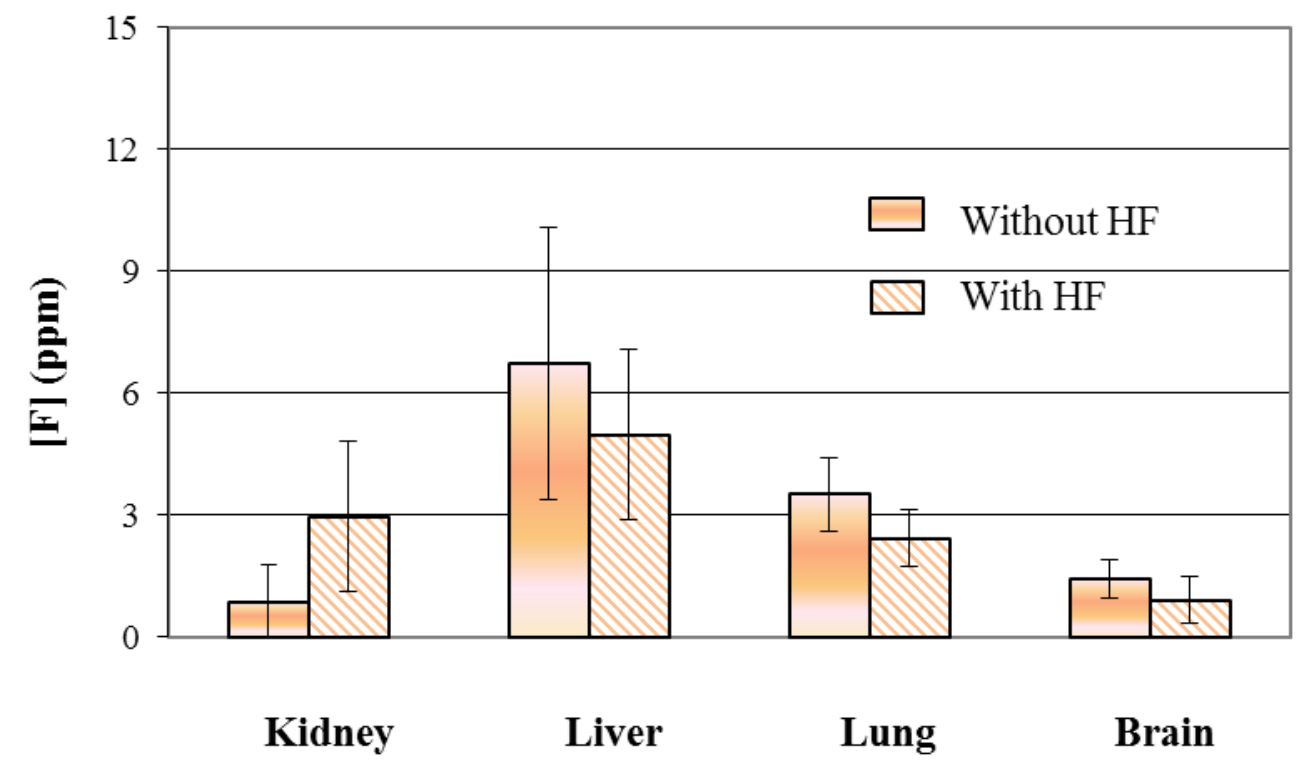

Fig. 5: Fluorine content in organs of rats euthanized after 13 months. Bars mean S.D. No significant difference at 0.95 confidence level between implants treated or not with HF.

It can be seen that the $\mathrm{F}$ content in the different organs is independent of the presence of the $\mathrm{MgF}_{2}$ coating on the $\mathrm{Mg}$ implant. The in vivo degradation of the implants with and without treatment shows no clear protective effect of the $\mathrm{MgF}_{2}$ layer.

\section{Discussion}

The AZ31 Mg alloy is a suitable material to repair fractures mainly due to its mechanical properties and degradation ability (Carboneras et al., 2011a; Seitz et al., 2014). The biodegradation process, $60 \%$ after 13 months (Fig. 2c), is responsible for the presence of metallic traces accumulated in the organs. In this work the distribution of the metallic traces in different organs has been studied after 1, 9 and 13 months. Yuen (Yuen and Ip, 2010) established the theoretical maximum annual levels 
for no-observed-adverse-effect (NOAEL) for some degradable $\mathrm{Mg}$ alloy implants. Following Yuen's guidelines, the authors have analysed the metallic release from AZ31 alloy implants from the lowest element content in the alloy, in this case manganese, to the most dangerous and toxic for the body, aluminium.

Considering Mn from the point of view of toxicity, it is considered one of the least toxic metals when consumed orally (Nielsen, 1999; WHO, 1974), but fairly toxic when administered by inhalation (Hathcock, 2004). Workers exposed to atmospheres with extreme concentrations, e.g. in excess of $27 \mathrm{mg} / \mathrm{m}^{3}$ (Jankovic, 2005) (more than 400 times a normal ambient level) (WHO, 2000) have developed neurotoxicity (manganic madness) with tremors similar to Parkinson's (ATSDR, 2012; Hathcock, 2004).

The maximum tolerable Mn dose has been set theoretically at $710^{-3} \mathrm{mg} \mathrm{kg}^{-1} \mathrm{~d}^{-1}$ (Yuen and Ip, 2010). After a year and considering the rat weight (200 g), this means that the maximum theoretical dose is $5.1110^{-1} \mathrm{mg}$. On the other hand, the AZ31 alloy (28 mg in our experiments) contents 0.22 $\% \mathrm{Mn}$ so this means $6.1610^{-2} \mathrm{mg}$. The tolerable dose is equivalent to 13.8 times the weight of our implant, since it is only $60 \%$ degradated after 13 months (8.3 times if $100 \%$ implant were released in one year). Mn is excreted in faeces after being stored in bile by the liver, so special care must be taken in patients with impaired liver function.

The second element to be considered has been $\mathrm{Zn}$, which is an essential element, so problems are usually related with a deficiency. Only the inhalation of extremely high concentrations can produce illness such as reversible zinc fever (Hildebrand and Hornez, 1998). In accordance with Yuen (Yuen and Ip, 2010), the maximum tolerable $\mathrm{Zn}$ dose has been set theoretically at $5.5310^{-2} \mathrm{mg} \mathrm{kg}^{-1}$ $\mathrm{d}^{-1}$ or, in our case, $4.04 \mathrm{mg}$ in a year (for a $200 \mathrm{~g}$ rat). In our $28 \mathrm{mg}$ implant with a $\mathrm{Zn}$ content of $0.78 \%$, there are $2.1810^{-1} \mathrm{mg}$. The tolerable dose would be 30.8 times the weight of the implant material inserted in this study (18.5 times if $100 \%$ implant were released in one year). Despite 
using alloys with $6 \%$ of this metal (more than 7 times the $\mathrm{Zn}$ content in our AZ31 alloy), Yu (Yu et al., 2013) considered it to be non-toxic, in fact quite the reverse, as it stimulates bone formation.

With regard to $\mathrm{Mg}$, although the literature reports toxic effects (EGVM, 2003; WHO, 2004) or even mortal effects (Birrer et al., 2002; Harper and Eley, 2002) when administered at very high doses, moderate increases in $\mathrm{Mg}$ contents do not cause toxicity in cell cultures (Carboneras et al., 2011b; Feyerabend et al., 2010; Lozano et al., 2013; Rezwan et al., 2006; Valentini et al., 2007) or in the human body (Li et al., 2004; Saris et al., 2000; Song, 2007). In other studies, Mg alloys implanted in vivo promote bone growth in their vicinity (Li et al., 2008; Witte et al., 2007a; Xu et al., 2007).

Studies on the short-term toxicity of Mg administered intravenously demonstrated that the lethal dose value (LD50) in rats is $174 \mathrm{mg} \mathrm{kg}^{-1}$ in females and $206 \mathrm{mg} \mathrm{kg}^{-1}$ in males (WHO, 2004). For a $200 \mathrm{~g}$ rat, this means between $35-40 \mathrm{mg}$ in a single dose. As $\mathrm{Mg}$ is released gradually, and $\mathrm{Mg}$ levels in the blood are regulated by the kidneys, the excess is excreted in urine (Reifenrath et al., 2011; Xu et al., 2007). Moreover, the skeleton also sequesters this metal, given that close to $50 \%$ of $\mathrm{Mg}$ in the body is stored in the bones (Rezwan et al., 2006).

According to Yuen (Yuen and Ip, 2010), annual insertion of implants with 64-73 $\mathrm{g} \mathrm{Mg}$ is considered tolerable in humans. That would be equivalent to implants with $180-200 \mathrm{mg} \mathrm{Mg}$ in one year in the experimental animal design proposed in this research. Our AZ31 implant contains less than $27 \mathrm{mg} \mathrm{Mg}$, i.e. 12 times less than the safe dose proposed by Yuen (7 times if $100 \%$ implant were released in one year).

In view of the above, it seems reasonable to rule out any toxic effect of the levels of $\mathrm{Mg}, \mathrm{Mn}$ or $\mathrm{Zn}$ used in the implants in this work on the proposed animal model.

With regard to $\mathrm{Al}$, this element is potentially neurotoxic in humans and laboratory animals (ElDemerdash, 2004) and has been shown to accumulate in organs such as the brain, bones, kidneys and blood (Oteiza et al., 1993). Al produces reactive oxygen species (ROS) and free radicals (Nehru and Anand, 2005; Prakash and Rao, 1995; Ranjbar et al., 2008; Strong et al., 1996) that 
cause the peroxidation of lipids (LPO), proteins and DNA. Numerous studies have been carried out on rats, establishing a relationship between aluminium and an increase in LPO and inhibition of antioxidant enzymes in the brain, liver and kidneys (Abubakar et al., 2004; Bhalla and Dhawan, 2009; Kaneko et al., 2007; Luo et al., 2007; Mahieu et al., 2009; Mohammadirad and Abdollahi, 2011; Ranjbar et al., 2008; Sanchez-Iglesias et al., 2009; Sharma and Mishra, 2006; Sharma et al., 2007; Stevanovic et al., 2009; Zatta et al., 2002; Zatta et al., 2000). Al is also suspected to play a part in neurodegenerative diseases like Alzheimer's (Bonnefont-Rousselot et al., 2004; Bulat et al., 2008; Gupta et al., 2005; Liao et al., 2006; Sargazi et al., 2006; Yuen and Ip, 2010; Zatta, 2006), Parkinson's and dementia (Erasmus et al., 1995), as well as in knowledge and behavioural deficits (Altmann et al., 1999; Sjögren et al., 1997) and hepatotoxicity (Chainy et al., 1996). A link has also been established between LPO in the brain and the appearance of Alzheimer's (Xie and Yokel, 1996).

The total $\mathrm{Al}$ content in the human body is estimated to be between $30-50 \mathrm{mg}$, of which almost half is in the skeleton and $25 \%$ in the lungs (Ganrot, 1986). De Broe (1986) reported different values, finding $40 \%$ of $\mathrm{Al}$ in bones, $40 \%$ in muscles, and only $1 \%$ in the brain, $1 \%$ in the liver and $12 \%$ in the lungs.

The maximum tolerable $\mathrm{Al}$ dose in rats has been set theoretically at $1.6410^{-2} \mathrm{mg} \mathrm{kg}^{-1} \mathrm{~d}^{-1}$ (Yuen and Ip, 2010). This means $1.19 \mathrm{mg}$ in $200 \mathrm{~g}$ of rat after a year. A WDXRF analysis of $28 \mathrm{mg}$ implant yields a level of $3.37 \%$, i.e., $0.94 \mathrm{mg} \mathrm{Al}$ in all the implant. Yuen uses very strict safety limits for $\mathrm{Al}$, always at the theoretical lower limit, prioritising safety. He also adds a safety factor of 10 times in order to absorb possible inter-population variations (the chance that some individuals may be 10 times more sensitive than those considered in the study). If this safety factor was not taken into account, the equivalent would be approximately 21 times that used here (12 times if $100 \%$ implant were released in one year). 
Taking into account possible toxicity problems related with $\mathrm{Al}$, together with its statistically significant difference, an exhaustive analysis has been made of its presence in the different organs. Table 2 shows the Al content in different organs for both the control rats and those fitted with implants. The Al content has risen in all the organs of the rats with implants, though the brain is the only organ where these differences are not significant.

This is in agreement with other studies using different types of implants, where the spleen is seen to be the organ in which the greatest amounts of trace ions accumulate (Debroe et al., 1986; Sarmiento-Gonzalez et al., 2009; WHO, 1974), probably due to its relationship with the immune system. This mechanism concords with Witte's findings in rabbits (Witte et al., 2007b), where the corrosion products containing $\mathrm{Al}$ that remained in the implant area were absorbed by macrophages. The highest content in absolute terms is found in the lungs, but the increase here has been moderate, as this is where the highest base level was found in the controls. This is in agreement with the findings of other authors (Yu et al., 2013).

With regard to the liver and spleen, the presence of Al may be explained as part of the body's excretion process, limiting $\mathrm{Al}$ toxicity in these organs, as pointed out by De Broe (Debroe et al., 1986), whereby "the sequestration of aluminium in the liver by lysosomes of hepatocytes and Kupffer cells, and in the spleen by macrophages, might explain the absence of proven toxicity for liver or spleen".

It is not easy for $\mathrm{Al}$ to enter the brain, as the blood-brain barrier impedes its passage (Yokel et al., 1999; Yokel and McNamara, 2001; Zatta et al., 1991). At the same time, the rate of elimination of Al from the brain is low (Sanchez-Iglesias et al., 2007; Yokel et al., 1999) and it is suspected that it may build up there over the individual's lifetime (Ganrot, 1986; Markesbery et al., 1984; Priest, 2004).

Average Al values in the brain of healthy humans have been determined in previous studies as being between 1-5 ppm (dry weight) (Bjertness et al., 1996; Hamilton et al., 1973; Markesbery et 
al., 1984; Tipton and Cook, 1963). Our data, which yields a value of $3.11 \mathrm{ppm}$ (dry weight) in the brain, may be considered to be within the range of normal values, although care must be taken to ensure that the number and size of inserted implants does not exceed the safety limit.

The Al values found in the different studied organs (Table 2) indicate that while a perceptible increase has taken place (column [a] of Table 2), only a tiny amount of the original mass of the implants has been retained in these organs (column [c] of Table 2). A $28 \mathrm{mg}$ implant with $3.37 \%$ $\mathrm{Al}$ is equivalent to $0.94 \mathrm{mg} \mathrm{Al}$, and the sum of the recovered $\mathrm{Al}$ from the sampled organs represents $3.95 \%$ of the total amount theoretically available (column [d] of Table 2).

These results agree with existing data from studies of parenteral medication, which is the most similar way to an implant for $\mathrm{Al}$ to enter the blood. In healthy adults $99 \%$ of this $\mathrm{Al}$ is eliminated through the kidneys (in urine) and to a lesser extent also through the liver (in bile) (HernandezSanchez et al., 2013). In studies of direct injection of $\mathrm{Al}^{25}$ in humans, after 24 hours only $0.5 \%$ remained in the blood (Priest et al., 1995; Priest et al., 1991), so its removal is very efficient. This effective functioning of the excretory system, together with the deposition of corrosion products in the vicinity of the implant, are the two main mechanisms that explain the relatively low $\mathrm{Al}$ concentration in the studied organs, in line with Witte's remarks (Witte et al., 2007b) that "only a small portion of ionic aluminium is bound to albumin and is transported out of the blood mainly into the skeleton, liver, kidneys, and brain, and in much smaller amounts into other soft tissues". Only in cases of diminished renal function (e.g. in elderly persons, patients with damaged kidneys, newborn children) does $\mathrm{Al}$ tend to accumulate in the body (Gura, 2010; Klein, 2003).

\section{Time influence}

The influence of time on the accumulation of metallic traces in the complete set of organs was studied. Only Al presents a statistically significant increase after 13 months. Great caution is advisable in this respect, since it is not known whether Al would continue to accumulate after longer times not considered in this study. Nevertheless, although all the organs show significant 
differences (ANOVA $\leq 0.05)$ between 0 and 13 months, the brain $(\rho=0.086)$ is an important exception considering that there seems to be a certain stabilisation after the ninth month. Of all the organs analysed, in absolute values $\mathrm{Al}$ is seen to accumulate most in the liver, (column [d] of Table 2). This is due to the greater weight of the liver compared to the other organs analysed (column [b] of Table 2). The $\mathrm{Al}$ excess in the liver is related to the known excretory function.

It is difficult to compare these results with data published in the literature as this is a pioneering work for such long testing times in animal experimentation. For shorter implantation times, Witte (Witte et al., 2007b), working with rabbits, found little migration of $\mathrm{Al}$ particles to tissues close to the implant site, and the gradual disappearance of Al between 3 to 6 months.

\section{Bone fracture influence}

The innovative aspect of the research carried out in this work is that it seeks to approximate a real situation of use of this material in fracture synthesis. To evaluate the influence of bone fracture on the ion release, a controlled fracture was performed in some of the experimental animals. The ANOVA results of the comparison between rats with and without bone fracture for each studied metallic element and organ show no significant differences (at $95 \%$ confidence) that could be attributed to the fracture factor.

The relatively slow biodegradation process of the material is compatible with the fracture consolidation process, without loss of mechanical or functional properties.

\section{HF treatment influence}

Fluoride is a natural anion within the skeleton and teeth, so the release of fluoride ions into the organism is expected to be harmlessness (Thomann et al., 2010). For example, MgCa alloy cylinders (Thomann et al., 2010) or LA63 scaffolds (Schilling et al., 2013) coated with fluoride have shown good biocompatibility in vivo. Thomann supposed that $\mathrm{F}$ was partly resorbed and evacuated. Elimination of $\mathrm{F}$ takes place via urine, faeces, etc., but the kidneys are the organs that play the most important role in its elimination (Thomann et al., 2010). This is in agreement with our 
results, as differences have not been seen in the $\mathrm{F}$ content in the organs irrespective of the presence or absence of the $\mathrm{MgF}_{2}$ coating on the AZ31 alloy implant (Fig. 5).

On the other hand, chronic excessive fluoride intake may result in fluorosis (Yang et al., 2011). Chronic fluorosis is a slow and progressive process causing symptoms related to muscle-skeletal and dental systems. Damage caused by chronic fluorosis has also been reported in many tissues including the kidney, liver and brain (Oncu et al., 2006). For this reason, F accumulation in these organs has also been studied (Fig. 5).

The results obtained with respect to the influence of prior treatment of the AZ31 implants with HF do not reflect a protective effect of the $\mathrm{MgF}_{2}$ layer on the AZ31 implant surface and no clear difference is seen between the ANOVA for each individual element (Fig. 5).

These results are in disagreement with Witte (Witte et al., 2008), who used a fluoride layer that slowed implant degradation, but agree with the findings of Thomann (Thomann et al., 2010), who reported no decrease in degradation despite the continuing presence of the fluoride layer after six months of implantation. According to Thomann (Thomann et al., 2010) there seems to be barely any degradation of the $\mathrm{MgCa} 0.8$ inside the bone medullary cavity. Our biodegradation results are different because both the tested alloy composition (AZ31) and implantation time (13 months) are different to those considered by Thomann. In our studies, biodegradation after 13 months reaches values of around $60 \%$ of the implant, as can be seen in Fig. 2c. The conclusion under this heading is that the addition of a protective $\mathrm{MgF}_{2}$ layer does not decrease the accumulation levels in organs of the studied traces, in contrast to previous in vitro results (Carboneras et al., 2011a; Carboneras et al., 2011b; Lozano et al., 2013), so in vivo degradation must depend on other parameters that have not yet been identified. These different behavior shows that an important variable that can control the biodegradation rate is the electrolyte thickness, i.e., the volume of fluid that bathes the surface of the implant (Montoya et al., 2014). This variable can even be more important in the biodegradation than the presence of the $\mathrm{MgF}_{2}$ coating. 
In vivo degradation of $\mathrm{Mg}$ implants does not provide evidence of significant toxic levels of metallic trace accumulation in organs that induce serious alterations in their normal function. Nevertheless, it is worth noting the great ability of the organs of lodging metallic traces when blood magnesium levels and the inner organs are unaltered whereas the immediately surrounding tissue can be severely affected by some magnesium alloys (Dziuba et al., 2013).

\section{Conclusions}

1) After a long implantation time, insertion of the AZ31 implant as an endomedullary pin and its subsequent biodegradation leads to the statistically significant accumulation of $\mathrm{Al}$ traces in all the studied organs.

2) After 13 months, the increase in $\mathrm{Al}$ recovered from all the sampled organs represents $3.95 \%$ of the amount contained in the AZ31 implant. Al accumulates in a statistically significant way in all the organs except the brain.

3) The presence of a fracture in the bone where the implant is inserted has not led to a significant increase in metallic traces in the different organs compared to the animals without bone fracture. This is the case for all the elements and all the organs.

4) Prior treatment of the implant with HF does not lead to significant differences in the accumulation of metallic traces after long implantation times. The protective effect of the $\mathrm{MgF}_{2}$ layer found in vitro has not been reproduced in this in vivo study.

\section{Acknowledgements}

The authors are grateful to the MINECO, Spain, for financial support by projects MAT 200806719-C03-01-03 and MAT 2011-29152-C02-01.

\section{References}

Abubakar MG, Taylor A, Ferns GAA (2004) Regional accumulation of aluminium in the rat brain is affected by dietary vitamin E. Journal of Trace Elements in Medicine and Biology, 18:5359.

Altmann P, Cunningham J, Dhanesha U, Ballard M, Thompson J, Marsh F (1999) Disturbance of cerebral function in people exposed to drinking water contaminated with aluminium 
sulphate: retrospective study of the Camelford water incident. British Medical Journal, 319:807-811.

Alvarez-Lopez M, Dolores Pereda M, del Valle JA, et al. (2010) Corrosion behaviour of AZ31 magnesium alloy with different grain sizes in simulated biological fluids. Acta Biomaterialia, 6:1763-1771.

ATSDR (2012)Toxicological Profile for Manganese. (A.f.T.S.a.D.R. (ATSDR). ed), US, pp 14-16.

Bhalla P, Dhawan DK (2009) Protective Role of Lithium in Ameliorating the Aluminium-induced Oxidative Stress and Histological Changes in Rat Brain. Cellular and Molecular Neurobiology, 29:513-521.

Birrer RB, Shallash AJ, Totten V (2002) Hypermagnesemia-induced fatality following Epsom salt gargles. Journal of Emergency Medicine, 22:185-188.

Bjertness E, Candy JM, Torvik A, et al. (1996) Content of brain aluminum is not elevated in Alzheimer disease. Alzheimer Disease \& Associated Disorders, 10:171-174.

Blaker JJ, Maquet V, Jerome R, Boccaccini AR, Nazhat SN (2005) Mechanical properties of highly porous PDLLA/Bioglass (R) composite foams as scaffolds for bone tissue engineering. Acta Biomaterialia, 1:643-652.

Bonnefont-Rousselot D, Chantalat-Auger C, Teixeira A, Jaudon MC, Pelletier S, Cherin P (2004) Blood oxidative stress status in patients with macrophagic myofasciitis. Biomedicine \& Pharmacotherapy, 58:516-519.

Bulat P, Potkonjak B, Dujic I (2008) Lipid peroxidation and antioxidative enzyme activity erythrocytes of workers occupationally exposed to aluminium. Arhiv Za Higijenu Rada I Toksikologiju, 59:81-87.

Carboneras M, Garcia-Alonso MC, Escudero ML (2011a) Biodegradation kinetics of modified magnesium-based materials in cell culture medium. Corrosion Science, 53:1433-1439.

Carboneras M, Hernandez LS, del Valle JA, Garcia-Alonso MC, Escudero ML (2010) Corrosion protection of different environmentally friendly coatings on powder metallurgy magnesium. Journal of Alloys and Compounds, 496:442-448.

Carboneras M, Iglesias C, Perez-Maceda BT, et al. (2011b) Corrosion behaviour and in vitro/in vivo biocompatibility of surface-modified AZ31 alloy. Revista De Metalurgia, 47:212-223.

Castellani C, Lindtner RA, Hausbrandt P, et al. (2011) Bone-implant interface strength and osseointegration: Biodegradable magnesium alloy versus standard titanium control. Acta Biomater, 7:432-440.

Coedo AG, Dorado MT, Ruiz J, Escudero M, Rubio JC (1996) Evaluation of flow injection sample to standard addition method for the inductively coupled plasma mass spectrometric determination of aluminium in biological tissues. Journal of Mass Spectrometry, 31:427432.

Chainy GBN, Samanta L, Rout NB (1996) Effect of aluminium on superoxide dismutase, catalase and lipid peroxidation of rat liver. Research Communications in Molecular Pathology and Pharmacology, 94:217-220.

Chaya A, Yoshizawa S, Verdelis K, et al. (2015) In vivo study of magnesium plate and screw degradation and bone fracture healing. Acta Biomaterialia, 18:262-269.

Chiu KY, Wong MH, Cheng FT, Man HC (2007) Characterization and corrosion studies of fluoride conversion coating on degradable Mg implants. Surface \& Coatings Technology, 202:590598.

Debroe ME, Vandevyver FL, Silva FJE, Dhaese PC, Verbueken AH (1986) Measuring aluminum in serum and tissues - overview and perspectives. Nefrologia, 6:41-46.

Donath K, Breuner G (1982) A method for the study of undecalcified bones and teeth with attached soft-tissues - the sage-schliff (sawing and grinding) technique. Journal of Oral Pathology \& Medicine, 11:318-326. 
Dziuba D, Meyer-Lindenberg A, Seitz JM, Waizy H, Angrisani N, Reifenrath J (2013) Long-term in vivo degradation behaviour and biocompatibility of the magnesium alloy ZEK100 for use as a biodegradable bone implant. Acta Biomaterialia, 9:8548-8560.

EGVM (2003)Magnesium Risk Assessments. In: Safe upper levels for vitamins and minerals (U.F.S. Agency, ed), pp 287-292.

El-Demerdash FM (2004) Antioxidant effect of vitamin E and selenium on lipid peroxidation, enzyme activities and biochemical parameters in rats exposed to aluminium. Journal of Trace Elements in Medicine and Biology, 18:113-121.

Erasmus RT, Kusnir J, Stevenson WC, et al. (1995) Hyperaluminemia associated with livertransplantation and acute-renal-failure. Clinical Transplantation, 9:307-311.

Feyerabend F, Fischer J, Holtz J, et al. (2010) Evaluation of short-term effects of rare earth and other elements used in magnesium alloys on primary cells and cell lines. Acta Biomaterialia, 6:1834-1842.

Feyerabend F, Witte F, Kammal M, Willumeit R (2006) Unphysiologically high magnesium concentrations support chondrocyte proliferation and redifferentiation. Tissue Engineering, 12:3545-3556.

Fischerauer SF, Kraus T, Wu X, et al. (2013) In vivo degradation performance of micro-arcoxidized magnesium implants: a micro-CT study in rats. Acta Biomater, 9:5411-5420.

Ganrot PO (1986) Metabolism and possible health-effects of aluminum. Environmental Health Perspectives, 65:363-441.

Gupta VB, Anitha S, Hegde ML, et al. (2005) Aluminium in Alzheimer's disease: are we still at a crossroad? Cellular and Molecular Life Sciences, 62:143-158.

Gura KM (2010) Aluminum contamination in products used in parenteral nutrition: Has anything changed? Nutrition, 26:585-594.

Hamilton EI, Minski MJ, Cleary JJ (1973) The concentration and distribution of some stable elements in healthy human tissues from the United Kingdom — an environmental study. Sci. Total Environ, 1:341-374.

Harper K, Eley BS (2002) Near-fatal hypermagnesaemia - Time to revisit over-the-counter medication. Samj South African Medical Journal, 92:211-212.

Hathcock J (2004) Vitamin and Mineral Safety. Washington, DC.

He Y, Tao H, Zhang Y, et al. (2009) Biocompatibility of bio-Mg-Zn alloy within bone with heart, liver, kidney and spleen. Chinese Science Bulletin, 54:484-491.

Hernandez-Sanchez A, Tejada-Gonzalez P, Arteta-Jimenez M (2013) Aluminium in parenteral nutrition: a systematic review. European Journal of Clinical Nutrition, 67:230-238.

Hildebrand H, Hornez JC (1998)Biological Response and Biocompatibility. In: Metals as Biomaterials (J.A. Helsen, H.J. Breme, eds), Wiley, pp 268.

Iglesias C, Bodelon OG, Montoya R, et al. (2015) Fracture bone healing and biodegradation of AZ31 implant in rats. Biomedical materials (Bristol, England), 10:025008-025008.

Jankovic J (2005) Searching for a relationship between manganese and welding and Parkinson's disease. Neurology, 64:2021-2028.

Kaneko N, Sugioka T, Sakurai H (2007) Aluminum compounds enhance lipid peroxidation in liposomes: Insight into cellular damage caused by oxidative stress. Journal of Inorganic Biochemistry, 101:967-975.

Klein GL (2003) Aluminum contamination of parenteral nutrition solutions and its impact on the pediatric patient. Nutrition in clinical practice : official publication of the American Society for Parenteral and Enteral Nutrition, 18:302-307.

Kraus T, Fischerauer SF, Hanzi AC, Uggowitzer PJ, Loffler JF, Weinberg AM (2012) Magnesium alloys for temporary implants in osteosynthesis: in vivo studies of their degradation and interaction with bone. Acta Biomater, 8:1230-1238. 
Li LC, Gao JC, Wang Y (2004) Evaluation of cyto-toxicity and corrosion behavior of alkali-heattreated magnesium in simulated body fluid. Surface \& Coatings Technology, 185:92-98.

Li Z, Gu X, Lou S, Zheng Y (2008) The development of binary Mg-Ca alloys for use as biodegradable materials within bone. Biomaterials, 29:1329-1344.

Liao Y-H, Hwang L-C, Kao J-S, et al. (2006) Lipid peroxidation in workers exposed to aluminium, gallium, indium, arsenic, and antimony in the optoelectronic industry. Journal of Occupational and Environmental Medicine, 48:789-793.

Lozano RM, Perez-Maceda BT, Carboneras M, Onofre-Bustamante E, Garcia-Alonso MC, Escudero ML (2013) Response of MC3T3-E1 osteoblasts, L929 fibroblasts, and J774 macrophages to fluoride surface-modified AZ31 magnesium alloy. Journal of biomedical materials research. Part A, 101:2753-2762.

Luo Y, Nie J, Gong Q-H, Lu Y-F, Wu Q, Shi J-S (2007) Protective effects of icariin against learning and memory deficits induced by aluminium in rats. Clinical and Experimental Pharmacology and Physiology, 34:792-795.

Mahieu S, del Carmen Contini M, Gonzalez M, Millen N (2009) Melatonin reduces oxidative damage induced by aluminium in rat kidney. Toxicology Letters, 190:9-15.

Manuel MV, Hort N (2011) Magnesium: An Essential Nutrient for a Good Biomaterial. Jom, 63:9999.

Markesbery WR, Ehmann WD, Alauddin M, Hossain TIM (1984) Brain trace-element concentrations in aging. Neurobiology of Aging, 5:19-28.

Mohammadirad A, Abdollahi M (2011) A Systematic Review on Oxidant/Antioxidant Imbalance in Aluminium Toxicity. International Journal of Pharmacology, 7:12-21.

Montoya R, Iglesias C, Escudero ML, Garcia-Alonso MC (2014) Modeling in vivo corrosion of AZ31 as temporary biodegradable implants. Experimental validation in rats. Materials Science \& Engineering C-Materials for Biological Applications, 41:127-133.

Nehru B, Anand P (2005) Oxidative damage following chronic aluminium exposure in adult and pup rat brains. Journal of Trace Elements in Medicine and Biology, 19:203-208.

Nielsen F (1999) Ultratrace elements. In: Modern nutrition in health and disease (M.E. Shils, J.A. Olson, M. Shike, A.C. Ross, eds), Williams \& Wilkins, Baltimore, pp 283-303.

Okazaki Y, Goth E (2008) Metal release from stainless steel, Co-Cr-Mo-Ni-Fe and Ni-Ti alloys in vascular implants. Corrosion Science, 50:3429-3438.

Okazaki Y, Gotoh E, Manabe T, Kobayashi K (2004) Comparison of metal concentrations in rat tibia tissues with various metallic implants. Biomaterials, 25:5913-5920.

Oncu M, Gulle K, Karaoz E, et al. (2006) Effect of chronic fluorosis on lipid peroxidation and histology of lung tissues in first and second generation rats. Toxicology and Industrial Health, 22:375-380.

Oteiza PI, Keen CL, Han B, Golub MS (1993) Aluminum accumulation and neurotoxicity in swisswebster mice after long-term dietary exposure to aluminum and citrate. Metabolism-Clinical and Experimental, 42:1296-1300.

Prakash NT, Rao KSJ (1995) Modulations in antioxidant enzymes in different tissues of marine bivalve perna-viridis during heavy-metal exposure. Molecular and Cellular Biochemistry, 146:107-113.

Priest ND (2004) The biological behaviour and bioavailability of aluminium in man, with special reference to studies employing aluminium-26 as a tracer: review and study update. Journal of Environmental Monitoring, 6:375-403.

Priest ND, Newton D, Day JP, Talbot RJ, Warner AJ (1995) Human metabolism of al-26 and ga-67 injected as citrates. Human \& Experimental Toxicology, 14:287-293.

Priest ND, Newton D, Talbot RJ (1991)Metabolism of aluminum-26 and gallium-67 in a volunteer following their injection as citrates. In: AEA Technology Report. 
Ranjbar A, Khani-Jazanib R, Sedighic A, Jalali-Mashayekhia F, Ghazi-Khansarid M, Abdollahie M (2008) Alteration of body total antioxidant capacity and thiol molecules in human chronic exposure to aluminum. Toxicological \& Environmental Chemistry, 90:707-713.

Reifenrath J, Bormann D, Meyer-Lindenberg A (2011)Magnesium alloys as promising degradable implant materials in orthopaedic research. In: Magnesium Alloys - Corrosion and Surface Treatments (F. Czerwinski, ed), pp 93-108.

Rezwan K, Chen QZ, Blaker JJ, Boccaccini AR (2006) Biodegradable and bioactive porous polymer/inorganic composite scaffolds for bone tissue engineering. Biomaterials, 27:34133431.

Rubio JC, Garcia-Alonso MC, Alonso C, et al. (2008) Determination of metallic traces in kidneys, livers, lungs and spleens of rats with metallic implants after a long implantation time. Journal of Materials Science-Materials in Medicine, 19:369-375.

Sanchez-Iglesias S, Mendez-Alvarez E, Iglesias Gonzalez J, et al. (2009) Brain oxidative stress and selective behaviour of aluminium in specific areas of rat brain: potential effects in a 6OHDA-induced model of Parkinson's disease. Journal of Neurochemistry, 109:879-888.

Sanchez-Iglesias S, Soto-Otero R, Iglesias-Gonzalez J, Barciela-Alonso MC, Bermejo-Barrera P, Mendez-Alvarez E (2007) Analysis of brain regional distribution of aluminium in rats via oral and intraperitoneal administration. Journal of Trace Elements in Medicine and Biology, 21:31-34.

Sargazi M, Shenkin A, Roberts NB (2006) Aluminium-induced injury to kidney proximal tubular cells: Effects on markers of oxidative damage. Journal of Trace Elements in Medicine and Biology, 19:267-273.

Saris NEL, Mervaala E, Karppanen H, Khawaja JA, Lewenstam A (2000) Magnesium - An update on physiological, clinical and analytical aspects. Clinica Chimica Acta, 294:1-26.

Sarmiento-Gonzalez A, Encinar JR, Marchante-Gayon JM, Sanz-Medel A (2009) Titanium levels in the organs and blood of rats with a titanium implant, in the absence of wear, as determined by double-focusing ICP-MS. Analytical and Bioanalytical Chemistry, 393:335-343.

Schilling T, Brandes G, Tudorache I, et al. (2013) In vivo degradation of magnesium alloy LA63 scaffolds for temporary stabilization of biological myocardial grafts in a swine model. Biomedizinische Technik. Biomedical engineering, 58:407-416.

Seitz JM, Eifler R, Bach F-W, Maier HJ (2014) Magnesium degradation products: Effects on tissue and human metabolism. Journal of biomedical materials research. Part A, 102:3744-3753.

Sharma P, Mishra KP (2006) Aluminum-induced maternal and developmental toxicity and oxidative stress in rat brain: Response to combined administration of Tiron and glutathione. Reproductive Toxicology, 21:313-321.

Sharma P, Shah ZA, Kumar A, Islam F, Mishra KP (2007) Role of combined administration of Tiron and glutathione against aluminum-induced oxidative stress in rat brain. Journal of Trace Elements in Medicine and Biology, 21:63-70.

Sjögren B, Elinder CG, Irgren A, McLachlan DRC, Riihimaki V (1997)Occupational aluminium exposure and its health effects. In: Research Issues in Aluminum Toxicity (R.A. Yokel, M.S. Golub, eds), Taylor \& Francis, Washington, U.S., pp 165-183.

Song G (2007) Control of biodegradation of biocompatable magnesium alloys. Corrosion Science, 49:1696-1701.

Staiger MP, Pietak AM, Huadmai J, Dias G (2006) Magnesium and its alloys as orthopedic biomaterials: A review. Biomaterials, 27:1728-1734.

Stevanovic ID, Jovanovic MD, Jelenkovic A, Colic M, Stojanovic I, Ninkovic M (2009) Effects of L-NAME, a non-speciric nitric oxide synthase inhibitor, on $\mathrm{AlCl} 3$-induced toxicity in the rat forebrain cortex. Journal of Veterinary Science, 10:15-22. 
Strong MJ, Garruto RM, Joshi JG, Mundy WR, Shafer TJ (1996) Can the mechanisms of aluminum neurotoxicity be integrated into a unified scheme? Journal of Toxicology and Environmental Health, 48:599-613.

Thomann M, Krause C, Angrisani N, et al. (2010) Influence of a magnesium-fluoride coating of magnesium-based implants $(\mathrm{MgCa} 0.8)$ on degradation in a rabbit model. Journal of Biomedical Materials Research Part A, 93A:1609-1619.

Tipton IH, Cook MJ (1963) Trace elements in human tissue. II. Adult subjects from the United States. Health physics, 9:103-145.

Valentini J, Schmitt GC, Grotto D, et al. (2007) Human erythrocyte delta-aminolevulinate dehydratase activity and oxidative stress in hemodialysis patients. Clinical Biochemistry, 40:591-594.

WHO (1974) Trace Elements In Human Nutrition - Report of a Who Expert Committee - WorldHealth-Organization. Who Chronicle, 28:41-42.

WHO (2000) Manganese. In: Air Quality Guidelines for Europe series. (W.H. Organization., ed), Copenhagen, Denmark, pp 154-156.

WHO (2004)Magnesium. In: Vitamin and mineral requirements in human nutrition (W.H. Organization, ed), Geneva, Italy, pp 217-229.

Witte F, Fischer J, Nellesen J, et al. (2006) In vitro and in vivo corrosion measurements of magnesium alloys. Biomaterials, 27:1013-1018.

Witte F, Hort N, Vogt C, et al. (2008) Degradable biomaterials based on magnesium corrosion. Current Opinion in Solid State \& Materials Science, 12:63-72.

Witte F, Ulrich H, Palm C, Willbold E (2007a) Biodegradable magnesium scaffolds: Part II: Periimplant bone remodeling. Journal of Biomedical Materials Research Part A, 81A:757-765.

Witte F, Ulrich H, Rudert M, Willbold E (2007b) Biodegradable magnesium scaffolds: Part I: Appropriate inflammatory response. Journal of Biomedical Materials Research Part A, 81A:748-756.

Xie CX, Yokel RA (1996) Aluminum facilitation of iron-mediated lipid peroxidation is dependent on substrate, $\mathrm{pH}$, and aluminum and iron concentrations. Archives of Biochemistry and Biophysics, 327:222-226.

Xu L, Yu G, Zhang E, Pan F, Yang K (2007) In vivo corrosion behavior of Mg-Mn-Zn alloy for bone implant application. Journal of Biomedical Materials Research Part A, 83A:703-711.

Yang S, Wang Z, Farquharson C, et al. (2011) Sodium fluoride induces apoptosis and alters bcl-2 family protein expression in MC3T3-E1 osteoblastic cells. Biochemical and Biophysical Research Communications, 410:910-915.

Yokel RA, Allen DD, Ackley DC (1999) The distribution of aluminum into and out of the brain. Journal of Inorganic Biochemistry, 76:127-132.

Yokel RA, McNamara PJ (2001) Aluminium toxicokinetics: An updated MiniReview. Pharmacology \& Toxicology, 88:159-167.

Yu K, Chen L, Zhao J, Wang R, Dai Y, Huang Q (2013) In vivo biocompatibility and biodegradation of a $\mathrm{Mg}-15 \% \mathrm{Ca}-3(\mathrm{PO} 4)(2)$ composite as an implant material. Materials Letters, 98:22-25.

Yuen CK, Ip WY (2010) Theoretical risk assessment of magnesium alloys as degradable biomedical implants. Acta Biomaterialia, 6:1808-1812.

Zatta P (2006) Aluminum and Alzheimer's disease: A Vexata Questio between uncertain data and a lot of imagination. Journal of Alzheimers Disease, 10:33-37.

Zatta P, Ibn-Lkhayat-Idrissi M, Zambenedetti P, Kilyen M, Kiss T (2002) In vivo and in vitro effects of aluminum on the activity of mouse brain acetylcholinesterase. Brain Research Bulletin, 59:41-45. 
Zatta P, Lain E, Cagnolini C (2000) Effects of aluminum on activity of Krebs cycle enzymes and glutamate dehydrogenase in rat brain homogenate. European Journal of Biochemistry, 267:3049-3055.

Zatta PF, M. N, Corain B (1991)Aluminium (III) toxicity and blood-brain barrier permeability. In: Aluminium in Chemistry, Biology and Medicine (M. Nicolini, P.F. Zatta, B. Corain, eds), Raven Press, New York, U.S., pp 97-112. 